\title{
Modelagem com o GeoGebra: uma possibilidade para a educação interdisciplinar?
}

\author{
Maria Alice Gravina* - gravina@ mat.ufrgs.br \\ Lucas de Oliveira Contiero ${ }^{* *}$ - lucascontiero@hotmail.com \\ Instituto de Matemática, UFRGS
}

Resumo: Este artigo discute o uso do software GeoGebra em atividade de modelagem que integra conteúdos de geometria e funções reais de variável real, com possíveis desdobramentos para trabalhos de natureza interdisciplinar. É apresentada uma experiência realizada em curso de licenciatura, na qual os alunos mostram, no processo de modelagem de movimentos, o desenvolvimento de habilidades que são características do raciocínio matemático - estabelecer relações, fazer conjeturas, resolver problemas.

\section{Palavras-Chave}

modelagem geométrica, geometria dinâmica, atividade interdisciplinar.

\section{Modeling with GeoGebra: an opportunity for an interdisciplinary education?}

Abstract: This article discusses the use of the GeoGebra software in a modeling activity that integrates geometry and functions of real variable, with possible ramifications for interdisciplinary work. It presents a modelling experiment developed in a geometry course in which the students showed the skills that are characteristic of mathematical reasoning.

\section{Keywords}

geometric modeling, dynamic geometric, interdisciplinary activity.

\section{Introdução}

Documentos do MEC (PCN, 2002) apontam para a necessidade de implementar-se nas escolas uma educação de natureza interdisciplinar. Uma tal educação com certeza se colocaria em maior sintonia com a complexidade do mundo em que vivemos, quanto aos desafios e problemas que nele se apresentam.

$\mathrm{Na}$ sociedade da informação, cada vez mais, aumenta o leque de competências exigido nos diferentes postos de trabalho e, frente aos problemas a serem resolvidos, o estado de prontidão intelectual torna-se uma competência crucial. Entenda-se por prontidão intelectual a capacidade de aprender rapidamente um novo assunto e dele fazer uso para resolver um problema que acaba de se apresentar.

Uma educação matemática que pretenda preparar os indivíduos para bem viverem nesta complexa sociedade deveria levar em consideração, de forma especial, o desenvolvimento de habilidades e atitudes que concorrem para tal prontidão intelectual. Quanto às habilidades, destacamos algumas delas: a habilidade para lidar com situações complexas, que exijam múltiplas estratégias de resolução; o saber expressar uma situação

*Professora do Curso de Licenciatura em Matemática e do Programa de Pós-Graduação em Ensino de Matemática do Instituto de Matemática da UFRGS.

**Aluno e bolsista-monitor do Curso de Licenciatura em Matemática do Instituto de Matemática da UFRGS. 
em linguagem matemática; e sobretudo, a aptidão para resolver problemas novos e não rotineiros, que dependem de raciocínios e conhecimentos matemáticos. E quanto às atitudes, algumas delas seriam: a valorização da matemática como ferramenta para resolução de problemas; a confiança em dispor de tal conhecimento quando necessário; as práticas cooperativas de enriquecimento intelectual advindo da confrontação de diferentes idéias e perspectivas.

O Curso de Licenciatura em Matemática da UFRGS tem, dentre os seus objetivos, a capacitação dos futuros professores no uso de tecnologia informática como um importante recurso a ser integrado, no futuro, em suas salas aulas. Isto porque a tecnologia disponibiliza, cada vez mais, ferramentas que suportam experimentos de pensamento e a sua exteriorização através de objetos metafóricos, e desta forma a sala de aula pode se tornar um fértil terreno para o desenvolvimento intelectual dos alunos, na forma habilidades e atitudes que são necessárias ao pensamento matemático. E é interessante observar que, já nos anos 80, Papert (1988) vislumbrava este alcance da tecnologia informática no processo de aprendizagem ao falar de bricolagem ou pensamento concreto, como atitudes que tratam de criar modelos, fazer simulações e analogias. Já nos dizia ele:

Bricolage e pensamento concreto sempre existiram, mas foram marginalizados (...) pela privilegiada posição do texto. À medida que passamos para a era da informática e que meios novos e mais dinâmicos surgirem, isso mudará (p.156).

Neste artigo apresentamos uma experiência realizada, no ano de 2011, com alunos calouros do Curso de Licenciatura em Matemática, na disciplina MAT 01341- Geometria I, no espírito de provocar mudanças na sala-aula. Além do tradicional estudo da geometria euclidiana, na forma de axiomas, teoremas e demonstrações, os alunos desenvolveram projetos de modelagem de mecanismos ou de situações do quotidiano, fazendo uso de um software de geometria-dinâmica. Para bem realizar a modelagem, além dos conhecimentos de geometria, os alunos precisaram trabalhar com funções reais de variável real. As características dos projetos apresentados, para além da integração de conteúdos de geometria e funções, indicam possibilidades para trabalhos escolares de natureza interdisciplinar.

\section{Geometria, funções e modelagem}

De uma forma geral, o estudo da geometria escolar tem foco na apresentação de conceitos e propriedades geométricas, sem que haja maiores preocupações com o desenvolvimento do raciocínio geométrico. Os livros apresentam uma coleção de definições e as propriedades são tomadas como "fatos", sem que haja uma maior explicação. Claro reflexo desta situação é detectado nos desempenhos dos calouros que cursam a disciplina de Geometria I do Curso de Licenciatura em Matemática da UFRGS: esses alunos chegam a universidade desprovidos das habilidades necessárias à construção do conhecimento geométrico. Abstrair, generalizar, estabelecer relações, fazer conjeturas — as ações que caracterizam o processo de pensar matematicamente lhes são estranhas (Gravina, 2001).

Também o estudo de funções, na escola, se mantém fortemente associado a classificação dos diferentes tipos de funções - função afim, função quadrática, funções trigonométricas, função exponencial e logaritmo. Conforme constatação de Ponte (1990), 


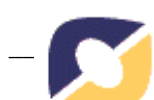

as funções tem ocupado um modesto lugar nos currículos de matemática. O conceito de função deveria ser transversal no programa de matemática escolar, tal a sua importância na sistematização de diferentes conteúdos: retas da geometria analítica são gráficos de funções que modelam fenômenos em que a proporcionalidade se faz presente; progressões são funções de variável discreta e modelam crescimentos populacionais; construções geométricas são funções que tem como leis "procedimentos com régua e compasso", estes alguns exemplos dentre outros tantos. Na escola, poucas são as situações desafiadoras em que os alunos, frente a um problema, precisam se debruçar sobre o assunto para bem identificar a função que modela o problema.

Com os recursos tecnológicos disponíveis, diferente poderia ser o processo de aprendizagem da matemática a se instalar nas escolas - tanto na provocação das habilidades cognitivas dos alunos, quanto na integração de conteúdos que normalmente são estudados separadamente e desta forma o contexto da aprendizagem também poderia se aproximar daquele de natureza interdisciplinar.

É a partir da análise de um particular software - o GeoGebra- que vamos ilustrar o potencial que temos nos recursos tecnológicos para que se desencadeiem mudanças nas práticas pedagógicas. Com o software GeoGebra, com interface na Figura 1, podemos trabalhar com geometria (Geo) e álgebra (Gebra). Nele, as figuras são produzidas através de menus em linguagem natural da geometria - ponto, reta passando por dois pontos, retas paralelas, retas perpendiculares, círculos, transformações geométricas, por exemplo.

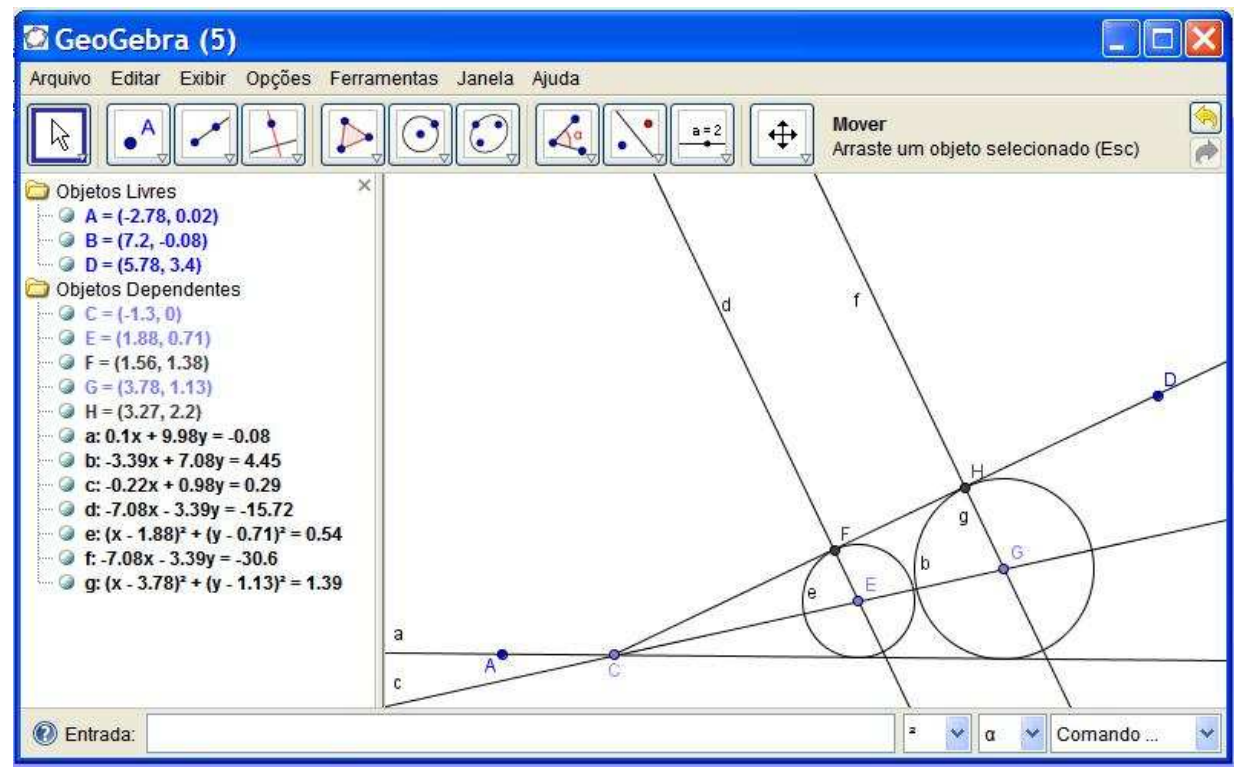

Figura 1: Interface do software GeoGebra

O GeoGebra e outros programas similares - os ditos softwares de geometria dinâmica - tem o interessante recurso de "estabilidade sob ação de movimento": feita uma construção, mediante movimento aplicado aos pontos que dão início a construção, a figura que está na tela do computador se transforma quanto ao tamanho e posição, mas preserva as propriedades geométricas que foram impostas no processo de construção, bem como as propriedades delas decorrentes. 
As figuras da geometria também podem ser estudadas sob o ponto de vista analítico. Para isto, tem-se na interface do software as opções "Exibir Eixos" e "Exibir Janela de Álgebra" e assim pode-se trabalhar, por exemplo, com as coordenadas dos pontos, com as equações das retas e círculos- este um conteúdo escolar que faz parte da geometria analítica. Também se pode usar o software para traçar gráficos de funções, a partir das leis que estabelecem relações entre variáveis.

Mas o foco deste artigo é discutir um uso diferente do GeoGebra. Trata-se do trabalho com modelagem. Dito de forma simplificada, um modelo matemático é uma representação, na linguagem da matemática, de certos aspectos de um fenômeno e tem por fim trazer um maior entendimento do fenômeno. Em particular, na modelagem geométrica temos uma representação que faz uso de pontos, retas, segmentos, perpendicularismo e paralelismo, dentre outros elementos. Ao nosso redor, muitos são os mecanismos nos quais as formas geométricas estão em movimento: nos ventiladores temos o movimento circular das hélices; em roldanas, observamos o movimento de sobe-desce de discos, que também giram; na praça de brinquedos temos o vai-vem do balanço, o sobe-desce da gangorra; na janela basculante vemos o movimento de giro de suas folhas; na escada rolante é o deslocamento vertical e horizontal dos degraus. É também rico o universo de movimentos do corpo humano, repleto de relações geométricas: o movimento de uma pessoa fazendo "polichinelo"; o movimento de pernas que correm ou que pedalam uma bicicleta; o movimento do braço que joga tênis.

Segundo Cundy (1997) aprendemos e entendemos melhor as propriedades de um modelo quando temos a oportunidade de vê-lo, manipulá-lo, e mais ainda, construí-lo. O processo de modelagem exige muita abstração e a transcrição da estrutura do mecanismo para a linguagem matemática torna-se também uma fonte de entendimento de seu funcionamento. Na construção do modelo no GeoGebra, a sincronia de movimentos é expressa com relações entre variáveis, usando-se geometria e/ou "leis" de funções. Exemplificamos: no "macaco" de um carro é o movimento de giro que desencadeia o movimento de deslocamento vertical. A Figura 2 apresenta um esboço do modelo: inicialmente tem-se um ponto $\mathrm{M}$ que se move em arco de círculo e este é o ponto que vai simular o movimento de giro; depois é acrescentado o losango articulado e, nele, o movimento circular do ponto $\mathrm{M}$ desencadeia o movimento retilíneo vertical do ponto $\mathrm{V}$ (este o ponto em que o carro se apóia no macaco). O movimento vertical do ponto $\mathrm{V}$ é garantido pela propriedade que caracteriza o losango - aquela de ter diagonais perpendiculares. É na transcrição do funcionamento do mecanismo para linguagem geométrica que se dá a explicitação desta propriedade, bem como a função "giro" X "deslocamento vertical".

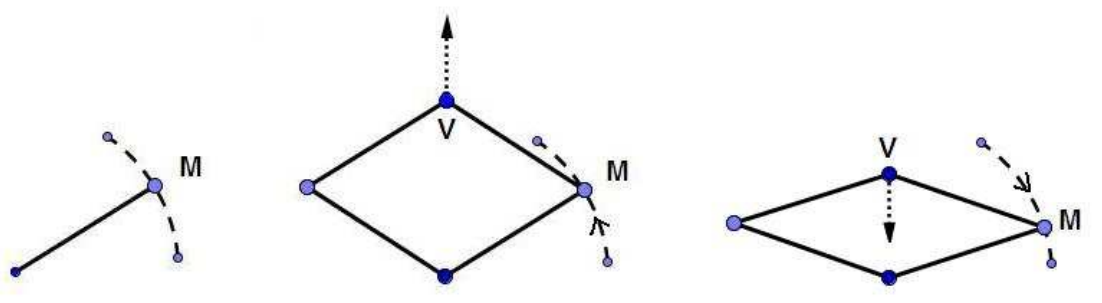

Figura 2: Esboço do modelo do macaco de carro 
Usando recursos do GeoGebra, também se pode construir o gráfico da função que relaciona as variáveis "giro" e "deslocamento vertical": no eixo Ox marca-se a medida do giro e no eixo Oy, a medida do deslocamento vertical (o software tem ferramentas para medir ângulos e segmentos) e assim é construído, via retas perpendiculares aos eixos, o ponto que desenha o gráfico da função. A Figura 3 mostra o gráfico da função e no modelo do mecanismo temos o triângulo retângulo que informa a lei da função, a saber, $y=L / 2$. sen $(\mathrm{x})$, onde $\mathrm{x}$ é a medida do ângulo de giro e y é a medida do deslocamento do ponto $\mathrm{V}$.
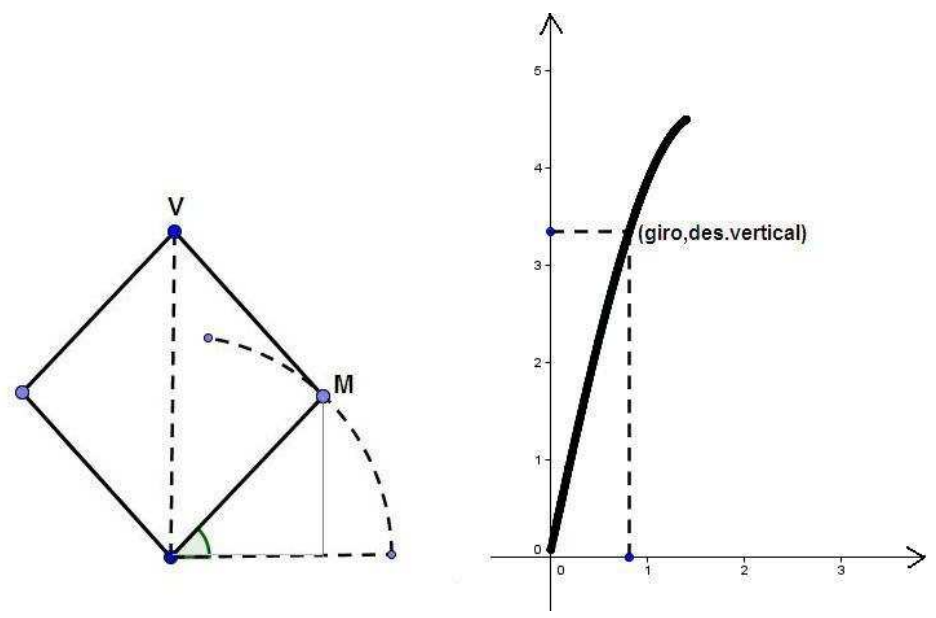

Figura 3: O gráfico da função "giro" x "deslocamento vertical"

Se mais complicado o movimento a ser modelado, mais interessante é a integração de conhecimentos de geometria e funções. Na próxima sessão vamos tratar de um tal exemplo.

\section{O desenrolar de um processo de modelagem}

$\mathrm{Na}$ apresentação dos projetos de modelagem desenvolvidos na disciplina de Geometria I, do curso de Licenciatura em Matemática, no primeiro semestre de 2011, os alunos mostraram que, na buscas de soluções aos problemas que se apresentaram, foram exigidos em habilidades e atitudes que caracterizam o pensamento matemático. No que segue vamos analisar o processo de modelagem vivenciado por uma dupla de alunos, que vamos identificar como Pa\&Ra.

A dupla Pa\&Ra tomou como desafio fazer a modelagem do movimento de planetas no sistema solar. O produto final deste trabalho está registrado na Figura 4, uma instancia particular da animação feita no GeoGebra onde se tem o movimento sincronizado de quatro planetas.

Dentre as primeiras atitudes da dupla, identificamos a cooperação e a contraposição de idéias e foi assim que estabeleceram a sua linha de ação: inicialmente modelar o movimento de um planeta, para depois resolver o problema da sincronia de movimento dos demais planetas. 


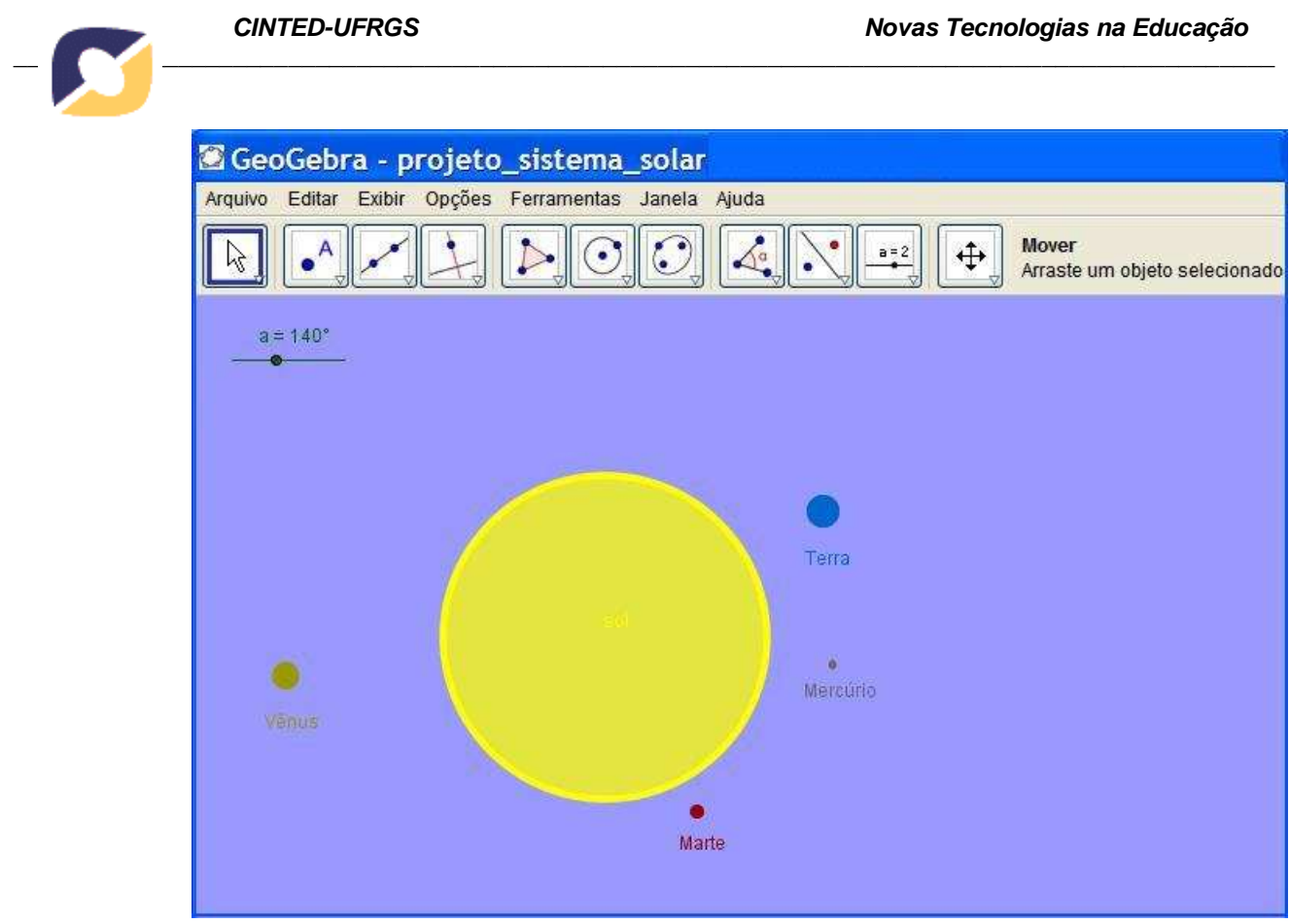

Figura 4: Modelagem de um sistema solar

Sabendo da necessidade de modelar uma trajetória elíptica para o primeiro planeta, a dupla de imediato fez uso do recurso de "Construção de cônica a partir de três pontos", disponível no GeoGebra e assim construiu uma primeira elipse. Usando a equação fornecida pelo software, um tanto complicada pois na forma $a \cdot x^{2}+b \cdot y^{2}+a \cdot x \cdot y+d \cdot x+e \cdot y=f, a$ dupla de imediato se concentrou em longas manipulações algébricas, de forma a controlar o movimento de um ponto sobre a curva - o primeiro planeta. Esta atitude revela o quanto a manipulação algébrica é uma atitude presente no "pensar matemático" dos alunos recémegressos da escola, um reflexo da ênfase com que manipulações, algoritmos e regras são trabalhados ao longo da vida escolar.

Como as manipulações algébricas se complicaram, a dupla reconsiderou a pertinência da estratégia adotada e foi com a disposição de enfrentar um novo problema que encaminharam uma resolução geométrica - olhar para a elipse como uma curva que é resultado da dilatação de um círculo em uma determinada direção. Para obter este efeito, foi utilizado o recurso "Reflexão com Relação a um Ponto", disponível no software e assim procederam com a construção: círculo; reta $\mathrm{r}$ passando pelo centro do círculo; ponto $\mathrm{C}$ sobre o círculo; reta s perpendicular à reta $\mathrm{r}$ por $\mathrm{C}$; ponto $\mathrm{D}$, intersecção das retas $\mathrm{r}$ e $\mathrm{s}$; ponto $\mathrm{E}$, reflexão do ponto $\mathrm{D}$ em relação ao ponto $\mathrm{C}$.
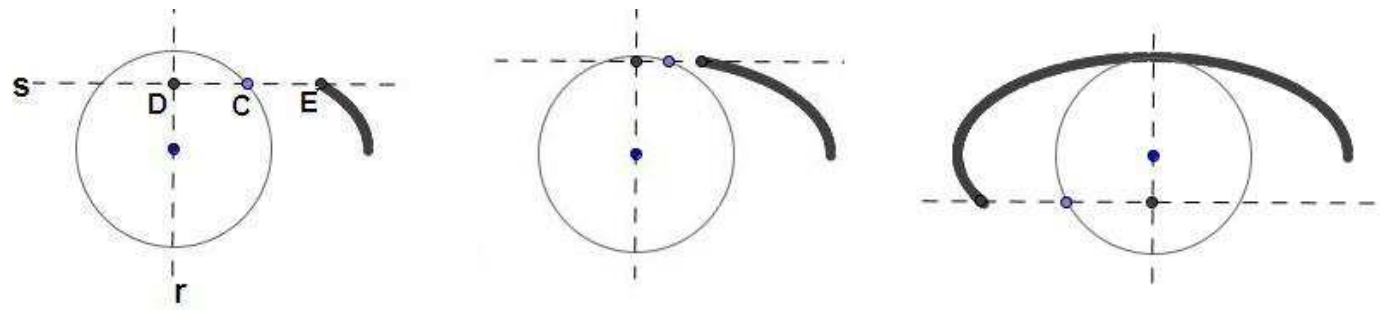

Figura 5: A elipse como resultado de dilatação horizontal do círculo 
Nesta construção, conforme o ponto $\mathrm{C}$ se movimenta no círculo, o correspondente ponto $\mathrm{E}$ se move em uma elipse, conforme ilustram as diferentes instâncias de movimento do ponto C, na Figura 5. Neste caso o círculo sofreu uma dilatação na direção horizontal, pelo fator 2 .

Resolvida a modelagem do movimento de um planeta, a dupla avançou com novas perguntas, na tentativa de implementar um modelo que se aproximasse da realidade: é possível fazer a modelagem das trajetórias dos diferentes planetas respeitando-se alguma escala na medida dos eixos das elipses? ; é possível ter-se o movimento dos planetas respeitando-se alguma escala de medida de velocidades? Após consulta a sites da Internet, as perguntas foram respondidas negativamente quanto a viabilidade de um tal modelo. As diferentes ordens de grandeza, tanto das trajetórias, quanto das velocidades dos planetas direcionou a modelagem para um sistema solar hipotético, com quatro planetas em movimento sincronizado. É interessante observar que foi com muita clareza que a dupla entendeu sobre a limitação do modelo a ser construído: usando dados reais, fizeram algumas estimativas de relações entre velocidades e entre tamanhos de trajetórias, e neste sentido passaram a ter uma compreensão mais acurada quanto a escalas e representações de fenômenos, este um assunto que Pa\&Ra reconheceram que foi pouco discutido na escola.

Neste ponto do trabalho a dupla já sabia que com quatro círculos distintos, concêntricos, poderiam construir as quatro trajetórias elípticas. Mas para colocar os quatro planetas em movimento, nas diferentes trajetórias e simultaneamente, a dupla precisou trabalhar com conteúdos de funções. Identificaram o recurso "Seletor" do GeoGebra como uma variável " $\mathrm{x}$ " a ser associada as diferentes velocidades dos planetas e foi interessante observar as dificuldades que foram sendo superadas por Pa\&Ra até que se tornasse claro como equacionar a "leis" das velocidades, para que o movimento dos planetas permanecesse contínuo no decorrer do tempo. Na Figura 6 temos a solução do problema para dois planetas.

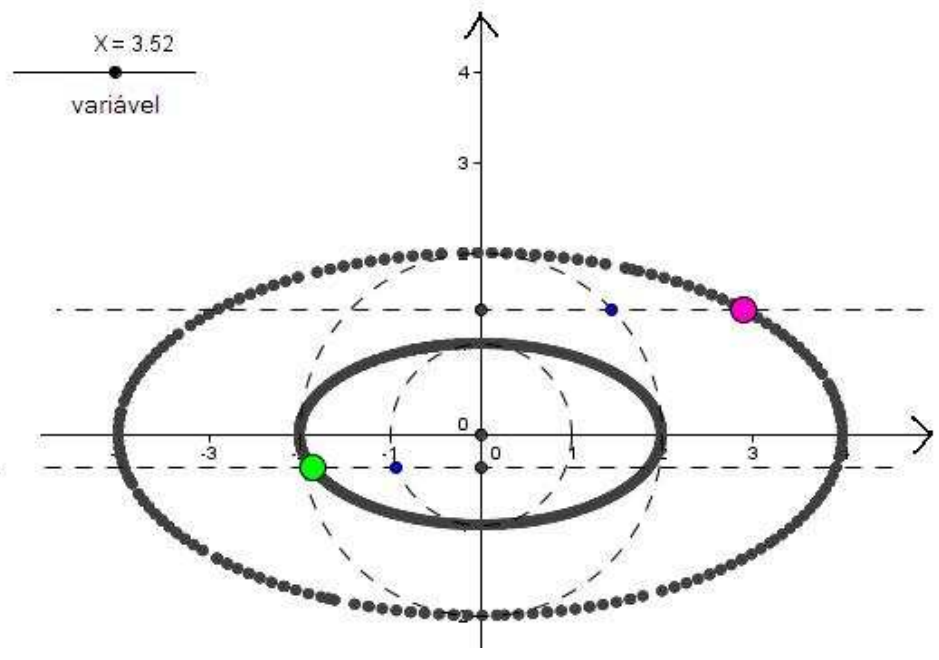

Figura 6: Movimento sincronizado de dois planetas

Enquanto a variável " $x$ " percorre o intervalo [0,2.Pi], o planeta "verde" descreve a trajetória elíptica menor, comandado pelo ponto "azul" de coordenadas $(\cos (\mathrm{x})$, $\operatorname{sen}(\mathrm{x}))$, que está percorrendo o círculo de raio 1; já o percurso do planeta "rosa", na elipse maior, é 
determinado pelo movimento do ponto "azul" de coordenadas $(2 \cdot \cos (2 . x), 2 \cdot \operatorname{sen}(2 . x))$ que percorre o círculo de raio 2. Neste modelo, os dois planetas tem trajetórias e velocidades diferentes e tem movimento comandado pela variável " $\mathrm{x}$ " - o movimento inicia quando é acionado o "Seletor", indicado na Figura 6.

Os conteúdos de geometria e funções que foram utilizados na construção deste modelo fazem parte daqueles que compõem o programa de matemática escolar. Mas no início do trabalho a dupla não mostrou desenvoltura para aplicar tal conhecimento. Foi ao longo do processo, com avanços e recuos nas estratégias escolhidas, que habilidades e atitudes foram sendo desenvolvidas. $\mathrm{Na}$ apresentação do projeto final a dupla falou com segurança sobre os problemas que foram atacados e sobre as soluções e conteúdos de matemática utilizados. Explicaram a escolha da unidade do sistema de coordenadas e a definição das coordenadas dos pontos que comandam o movimento dos quatro planetas, em função de uma variável "x" no intervalo [0,2.pi].

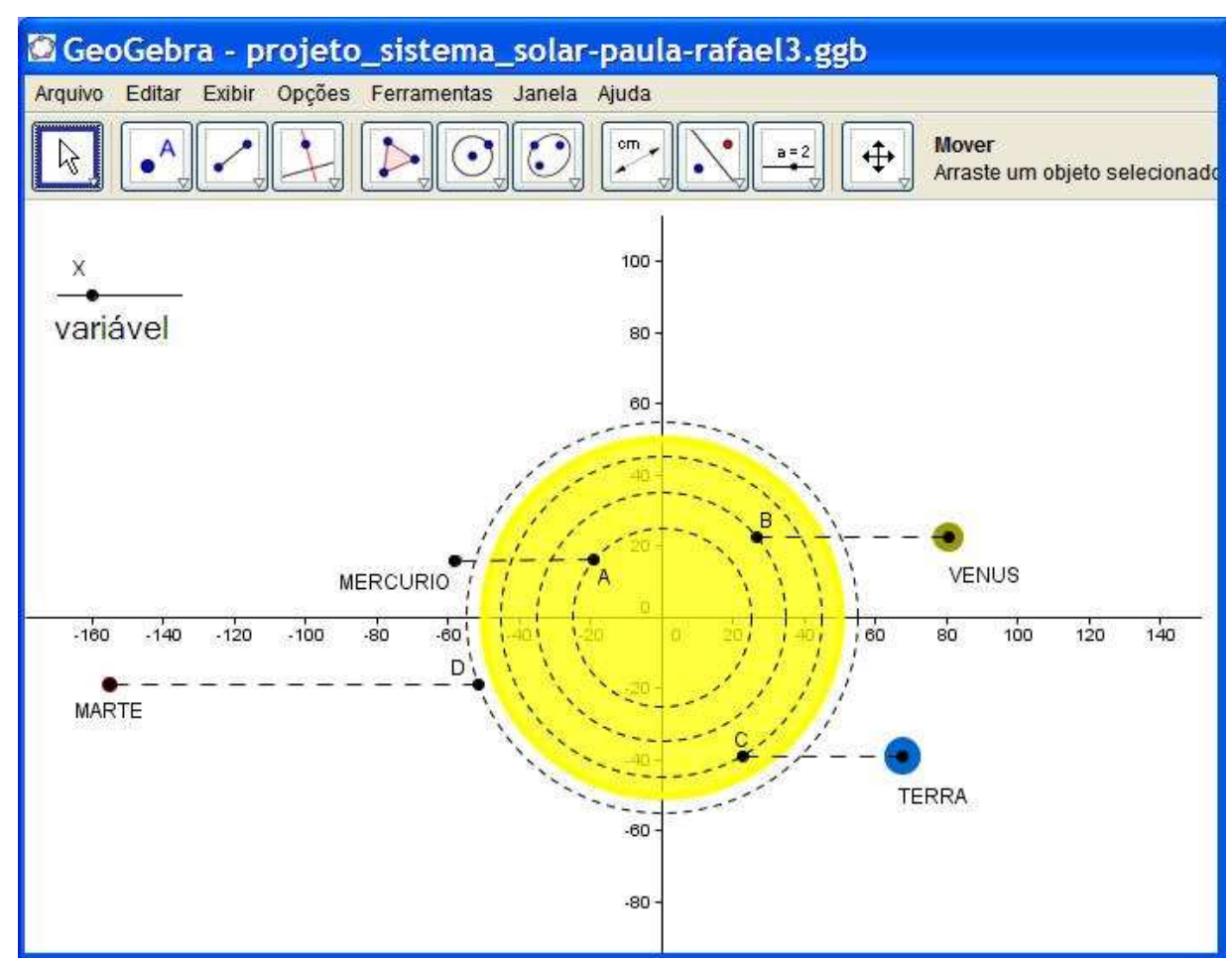

Figura 7: Geometria e funções no modelo do sistema solar

A Figura 7 apresenta a idéia que foi usada na construção do modelo: são quatro círculos concêntricos e em cada um deles tem-se um ponto que se move com certa velocidade, os pontos A,B,C e D; com o recurso de "Reflexão com Relação a um Ponto", a partir dos pontos A,B, C e D são obtidos os pontos que tem movimento em trajetórias elípticas, cada um deles correspondendo a um planeta. No modelo da figura os eixos maiores das elipses estão na relação 5:7:9:11 e as velocidades dos planetas estão na relação $5: 4: 3: 2$.

É claro que o modelo construído longe está da realidade. Mas sob o ponto de vista educativo, no que diz respeito ao desenvolvimento de habilidades e atitudes para resolver um problema de modelagem, fazendo uso de geometria e funções, o trabalho apresentado 
pela dupla Pa\&Ra atendeu o propósito desejado. O tema escolhido trás a possibilidade de desdobramentos para trabalho de natureza interdisciplinar: junto com os professores de geografia e de física, a imprecisão do modelo pode ser objeto de interessante discussão sobre a ciência e seus modelos. Com esta mesma possibilidade de desdobramentos para trabalhos interdisciplinares, citamos alguns dos demais projetos apresentados: a modelagem do movimento de carros em um cruzamento de ruas; o movimento de pernas em uma gangorra; os ponteiros e o pêndulo de um relógio; o movimento das bolas em um jogo de bilhar. Nestes diferentes modelos vemos assuntos que poderiam ser tratados, pelo menos, também sob o olhar da física.

Este trabalho de modelagem desenvolvido com os alunos se insere na proposta pedagógica do Curso de Licenciatura, especialmente no seu propósito de preparar os futuros professores para o uso da tecnologia informática em suas práticas pedagógicas. Durante o trabalho observamos a determinação dos alunos na busca de solução dos diferentes problemas que foram se apresentando e diríamos que a atividade desencadeou a situação a-didática discutida por Brousseau (1996) - é uma situação em que os alunos se engajam em uma tarefa não mais para atender a exigência do professor, mas movidos por interesse próprio, chamando a si a responsabilidade dos procedimentos de investigação, e desta forma estão dadas as condições para o desenvolvimento de habilidades e atitudes que caracterizam o raciocínio matemático. Esta vivência em trabalho de modelagem na disciplina de Geometria, uma das primeiras do Curso, tem a intenção de preparar os futuros professores para realizarem a transposição didática que vai propiciar, aos seus alunos, uma experiência similar.

\section{Considerações finais}

O software GeoGebra, com suas infinitas possibilidades, permite ao professor trabalhar com seus alunos em conteúdos importantes da geometria e de funções de variável real. A modelagem é uma possível abordagem e ela torna-se particularmente interessante porque possibilita modificar nosso olhar diante das situações cotidianas - ela nos faz perceber a presença da matemática em atividades do nosso dia-a-dia. É com este olhar de "geômetra" que vemos os alunos transformando objetos comuns em dinâmicos objetos geométricos com a ajuda do GeoGebra. Esta transformação dos objetos requer uma sutileza de olhar, requer o domínio de procedimentos geométricos e analíticos para identificar relações entre variáveis, e desta forma os alunos estão desenvolvendo habilidades e atitudes que são características do pensamento matemático - observar, conjeturar, relacionar, refinar suposições, desdobrar um problema em pequenos problemas. E discussões sobre o alcance do modelo produzido podem ser desencadeadoras de trabalhos de natureza interdisciplinar, ainda tão ausentes nas escolas.

\section{Referências Bibliográficas}

BROUSSEAU, G. Os diferentes papéis do professor, em Lerner,D. e outros, Didática da Matemática, Porto Alegre: Editora Artes Médicas, 1996.

CUNDY, H. M.; ROLLETT, A. P. Mathematical Models. Tarquin, 1997.

GRAVINA, M.A.; BARRETO, M.. Mídias Digitais na Educação Matemática. Material Didático. Curso de Especialização: Matemática, Mídias Digitais e Didática para a Educação Básica. Porto Alegre, UAB/IM/UFRGS,2010.Disponível em:<http://www6.ufrgs.br/espmat/disciplinas/midias_digitais_I/>

GRAVINA, M. A .Os ambientes de geometria dinâmica e o pensamento hipotético dedutivo, Tese de 
doutorado no Programa de PósGraduação em Informática na Educação/UFRGS, disponível em http://www.biblioteca.ufrgs.br/bibliotecadigital/, 2001.

PARÂMETROS CURRICULARES NACIONAIS (PCN), Matemática, Ensino Médio, Brasília,MEC, SEF, 2002.

PAPERT, S. The Children Machine: Rethinking Scholl in the Age of the Computers. New York USA : Harvester Wheatsheaf, 1988.

PONTE,J.P. O conceito de função no currículo de matemática. Educação e Matemática no.15, 1990 (3-9). 